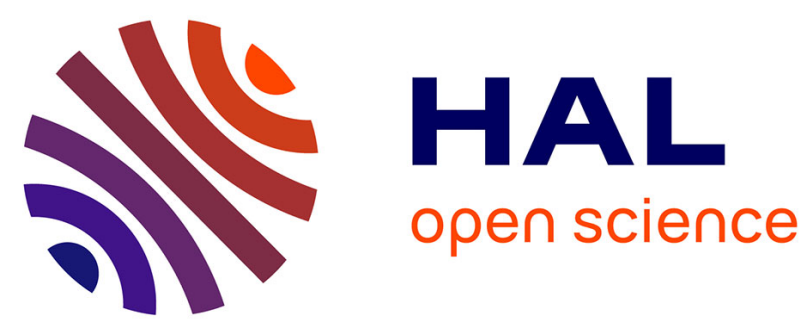

\title{
GENERALIZATION OF FRÖHLICH'S OPERATOR FOR THE ELECTRON-PHONON COUPLING IN POLAR CRYSTALS
}

U. Schröder, M. Weiss, R. Reiger, J. Page

\section{> To cite this version:}

U. Schröder, M. Weiss, R. Reiger, J. Page. GENERALIZATION OF FRÖHLICH'S OPERATOR FOR THE ELECTRON-PHONON COUPLING IN POLAR CRYSTALS. Journal de Physique Colloques, 1981, 42 (C6), pp.C6-496-C6-498. 10.1051/jphyscol:19816145 . jpa-00221210

\section{HAL Id: jpa-00221210 https://hal.science/jpa-00221210}

Submitted on 1 Jan 1981

HAL is a multi-disciplinary open access archive for the deposit and dissemination of scientific research documents, whether they are published or not. The documents may come from teaching and research institutions in France or abroad, or from public or private research centers.
L'archive ouverte pluridisciplinaire HAL, est destinée au dépôt et à la diffusion de documents scientifiques de niveau recherche, publiés ou non, émanant des établissements d'enseignement et de recherche français ou étrangers, des laboratoires publics ou privés. 


\title{
GENERALIZATION OF FRÖHLICH'S OPERATOR FOR THE ELECTRON-PHONON COUPLING IN POLAR CRYSTALS*
}

\author{
U. Schröder, M. Weiss, R.Reiger and J.B. Page**
}

Institut fïr Theoretische Physik, Universität Regensburg, D-8400 Regensburg, F.R.G.

**Physias Department, Arizona State University, U.S.A.

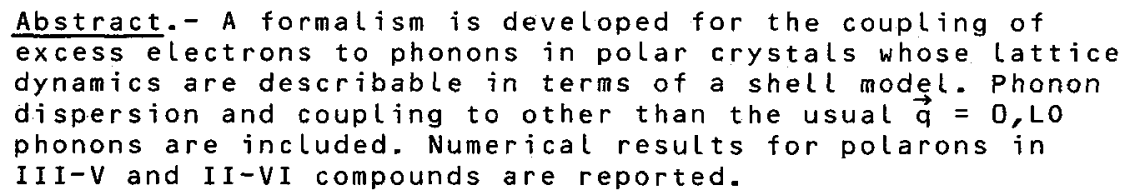

The interaction of an electron (or hole) with phonons in a polar semiconductor is usually described by Fröhlich's Hamiltonian ${ }^{1}$. This ansatz is very fruitful for the understanding of various problems of the solid state and leads, for example, to the concept of the large polaron. As an essential assumption, the Fröhlich Hamiltonian describes the lattice vibrations by a continuum model. In this paper we develop a theory for the electron-phonon interaction with the full lattice Hamiltonian, where the phonons are treated in the harmonic approximation and are described in terms of a shell model ${ }^{2,3}$.

We start from the Hamiltonian for the electron-phonon coupling given by

$$
H_{\text {el-phon }}=\sum_{l, b}\left\{V(\vec{r}, \vec{R}(l, b))-V\left(\vec{r}_{,} \vec{R}_{0}(l, b)\right)\right\},
$$

where $\vec{R}(l, b)$ denotes the position of the $b-t h$ ion in the $l-t h$ cell and $\vec{R}_{0}(L, b)$ its equilibrium position, and $\vec{r}$ is the position of the electron. We assume that the ions have the charge $z_{b} e$ and the electronic polarization $\vec{P}_{b}[\vec{u}(l, b)]$, which is a function of the displacements $\vec{u}(L, b)=\vec{R}(L, b)-\vec{R}_{0}(L, b)$. The potential energy is then given by

$$
V(\vec{r}, \vec{R})=-\frac{z_{b} e^{2}}{|\vec{r}-\vec{R}|}-\frac{e(\vec{r}-\vec{R}) \cdot \vec{P}_{b}(\vec{u})}{|\vec{r}-\vec{R}|^{3}} .
$$

In the continuum approximation $\vec{P}_{b}$ can be written in terms of the macroscopic constants $\varepsilon_{\infty}$ and $\varepsilon_{0}$. This leads to the well-known fröhlich Hamiltonian. A fully microscopic generalization of Fröhlich's treatment is difficult, since the full dielectric tensor must be used in 
order to account for local field effects. It is therefore convenient to describe the polarization field in terms of the shell model. We get

$$
\vec{P}_{b}=Y_{b} e(\vec{v}(l, b)-\vec{u}(l, b))
$$

where $Y_{b} e$ is the charge of the shell of atom $b$ and $\vec{v}(l, b)$ the displacement of the shell.

For small deviations from the equilibrium, we can expand the potential and use the harmonic approximation. We then write the displacements $\vec{u}(l, b)$ in terms of normal coordinates

$$
\vec{u}(l, b)=\vec{a}_{\vec{q}, j} \sqrt{\frac{\hbar}{2 N M_{b} \omega_{j}(\vec{q})}}\left\{\vec{e}_{c}\left(b \mid \vec{q}_{j}\right) e^{i \vec{q} \cdot \vec{R}_{0}(l, b)} a_{\vec{a} j}+h \cdot c \cdot\right\} .
$$

A similar formula holds for the shell displacements $\vec{v}(L, b)$ with $e_{s}(b \mid \vec{a} j)$ replacing $\vec{e}_{c}(b \mid \vec{q} j)$.

After an expansion into a fourier series and the evaluation of the sum over the lattice cells we get as a final result for the generalization of the fröhlich operator

$$
H_{\text {el-phon }}=\sum_{\vec{q}, j, \vec{G}}\left\{V_{\vec{q} j \vec{G}} \vec{a} \vec{q} j e^{i(\vec{q}+\vec{G}) \cdot \vec{r}}+h . c .\right\},
$$

with

$$
\begin{aligned}
& V_{\vec{a} j \vec{G}}=\sum_{b} \frac{-4 \pi e^{2} i}{\Omega_{0}} \sqrt{\frac{\hbar}{2 N M_{b} \omega_{j}(\vec{q})}} \frac{1}{|\vec{q}+\vec{G}|^{2}} e^{i \vec{G} \cdot \vec{R}_{0}(0, b)} \times \\
& \times(\vec{a}+\vec{G}) \cdot\left\{x_{b} \vec{e}_{c}(b \mid \vec{a} j)+Y_{b} \vec{e}_{s}(b \mid \vec{q} j)\right\} .
\end{aligned}
$$

Here $\vec{G}$ is a reciprocal lattice vector, $x_{b} e$ and $r_{b} e$ are the charges of the core and the shell of ion $b$, respectively, $M_{b}$ is the mass of ion $b$, $\Omega_{0}$ is the volume of the unit cell, and $N$ is the number of unit cells.

If the lattice dynamics of a crystal is known in terms of the shell model, the sums in (6) can be evaluated. Since the Hamiltanian contains the interaction with all phonons it also includes the piezoelectric coupling in crystals without inversion symmetry.

As a simple application, we investigate the case of the free polaron in semiconductors. Here the Hamiltonian is given by

$$
H=\frac{p^{2}}{2 m^{*}}+\sum_{q, j} \hbar \omega_{j}(\vec{q}) \underset{a}{a} \underset{a j}{\vec{a}} a_{a_{j}}+H_{e l-p h o n} .
$$

In the intermediate-coupling case the method of Lee, Low and Pines ${ }^{4}$ can easily be extended to this Hamiltonian. For the energy we get 
the result

$$
E=\frac{p^{2}}{2 m^{*}(1+c / 6)}-A \hbar \omega_{10} .
$$

Numerical results for $A$ and $C$ are given in $F i g s .1$ and 2 for some III-V and II-VI compounds. The continuum approximation yields $\alpha$ for both constants.
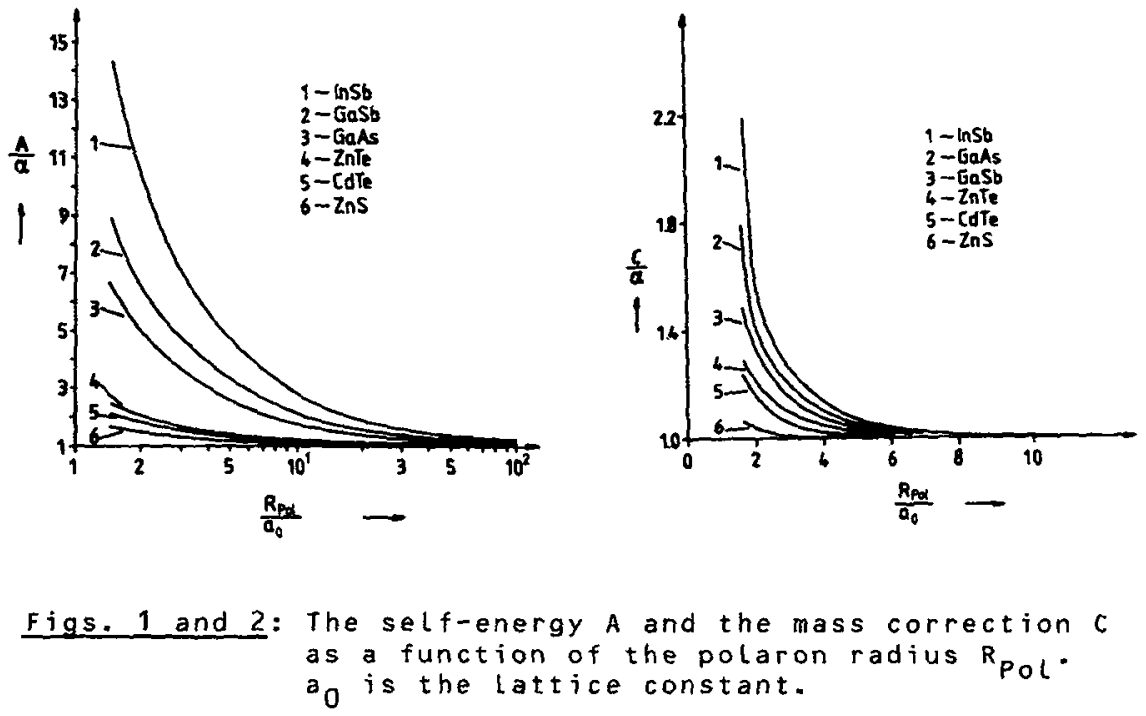

Since the polaron radii for electrons and holes range from 1.7 a (holes in ZnS) to 16 ag (electrons in InSb) the self-energy is considerably affected, but the polaron mass is only slightly different from that in the continuum approximation. A detailed analysis and an application to more polar crystals will be given in a forthcoming paper.

\section{References}

1 H. Fröhlich, H. Pelzer and S. Zienau: Philos.Mag. 41, 221 (1950).

2 See for example W. Cochran and R.A. Cowley in Handbuch der Physik Vol. 25/2a, (Springer, Heidelberg 1967).

3 The electron-phonon interaction in a shell model was also treated by J.M. Vail, J.Phys. C10, 2399 (1977), by a different approach.

4 T.D. Lee, F.E. Low and D. Pines: Phys.Rev. 90, 297 (1953).

* Work supported in part by grants from the Deutsche Forschungsgemeinschaft and the National science foundation. 